\title{
Psychosocial challenges and coping strategies of caregivers with family members under palliative care in Mufakose, Zimbabwe
}

\author{
Tsitsi Mguwata*, Great Zimbabwe University, Masvingo, Zimbabwe
}

\section{Suggested Citation:}

Mguwata, T. (2020). Psychosocial challenges and coping strategies of caregivers with family members under palliative care in Mufakose, Zimbabwe. Global Journal of Psychology Research: New Trends and Issues. 10(2), 117-127. https://doi.org/10.18844/gipr.v10i2.4797

Received 27, 2020; revised August 20, 2020; accepted September 16, 2020.

Selection and peer review under responsibility of Prof. Dr. Tulay Bozkurt, Istanbul Kultur University, Turkey. ${ }^{\circ} 2020$ Birlesik Dunya Yenilik Arastirma ve Yayincilik Merkezi. All rights reserved.

\begin{abstract}
This study sought to unearth the challenges and coping strategies of caregivers with family members under palliative care. As a high-density suburb, Mufakose is a dwelling place for the most economically marginalised members of the Zimbabwe urban dwellers. Having a family member under palliative care while being from a low social class has its ramifications and this was what the researcher sought to find out by carrying a qualitative research on six care givers $(n=6)$ sampled by purposive sampling. In-depth interviews guided by a self-constructed interview guide were used to collect data and thematic analysis was used for analysis. The interviews were carried out in Shona, the local language for the participants, and responses were later translated to English. The study indicated that the caregivers encountered a myriad of challenges ranging from social, economic and health problems. Disturbed sleeping patterns, weight loss, stress, inhibited social mobility, strained family relationships, limited health information about the illness, role conflict and increased financial constraints were the major cited challenges. The research established that caregivers are proactive and numerous coping strategies are used in dealing with the challenges. The coping strategies being used can be classified into appraisal-focused, problem-focused and emotionfocused. Although some coping strategies are maladaptive, most of them are quite adaptive, and with effective interventions the fortunes and lifestyle of caregivers can be overturned.
\end{abstract}

Keywords: Palliative care, family caregiver, coping strategy, challenges, home-based care.

* ADDRESS FOR CORRESPONDENCE: Tsitsi Mguwata, Great Zimbabwe University, Masvingo, Zimbabwe. 


\section{Background of the study}

The experience of caring for loved ones as they approach death can be one of deep fulfilment or significant trauma (Morris, 2003). According to Grant (2000), palliative care is the medical specialty focused on improving quality of life for people facing serious illness. Palliative care is provided by an interdisciplinary team of palliative care specialists, including doctors, nurses, social workers and others who work with a patient's other doctors to provide an extra layer of support, with the goal to improve quality of life for both the patient and their family. Illnesses most commonly treated by palliative care are heart disease, cancer, stroke, diabetes, renal disease, Parkinson's, Alzheimer's disease, human immune virus (HIV) and acquired immune deficiency syndrome (AIDS) (Donelan et al., 2002). Current estimates from the World Health Organisation show that more than 24 million people require palliative care at the end of life each year (Zimbabwe National Palliative Care, 2014).

Namisngo et al. (2008) note that non-communicable diseases, including cancer, diabetes, cardiovascular disease and chronic respiratory illness, are a growing challenge worldwide, accounting for $65 \%$ of all deaths. Eighty percent of these deaths occur in developing countries indicating the increase in the number of people in need of or receiving palliative care, thus calling for an exploration of the experience of family members of such populace. Research has noted an increase in the number ofter minal diseases in Africa, thus indicating a rise in people needing palliative care both the diseased and the family members. UNAIDS estimates that in 2003 there were 26.6 million people in subSaharan Africa living with HIV, and that there were 3.2 million new infections and 2.3 million AIDSrelated deaths, in addition to high HIV-related tuberculosis incidence in sub-Saharan Africa (Grant, 2002). A study of Zambian AIDS patients with cryptococcal meningitis found $100 \%$ mortality in 6 months, with $43 \%$ having received only palliation without curative intervention (Mwaba et al., 2001). While on the same note the WHO estimates that there are more than 0.5 million annual deaths from cancer in Africa (Morris 2003) and that by 2020, 70\% of new cancer cases will be in the developing world (Ramsay, 2001). Chokunonga (2006) states that the incidences of cancer cases in Zimbabwe were numbered as 4,015 in 2005 and 4,175 in 2006, respectively. This attests an increase in cancer cases in Zimbabwe, thus validating the exploration of the experience of family members of those suffering from cancer. As a member of sub-Saharan Africa, Zimbabwe shares the predicament of skyrocketing statics of terminal illness, thus an increase in people who need palliative care. The people affected do not usually suffer in isolation but have family members who see them through the journey until they eventually die. As noted by Musoke (2003), there is a clear need to focus on holistic palliative care in sub-Saharan Africa, despite the evidence that pain is the primary need, and psychological, spiritual and social care are crucial.

Hagedoorn et al. (2008) observed that terminal illnesses affect the family as a unit, rather than as isolated individuals, causing families to react to the diagnosis as an emotional system. This indicates psychological problems which may spill into physical health maladies. The first mental torture which may be a real bother to families of cancer/HIV patients is to doubt their capacity to administer proper care to the diseased relative. After conducting a research on families of cancer patients Maughan (2002) noted that family caregivers also worry about their ability to provide emotional and practical support to the patient, and about the potential loss of their relative. This anxiety can hinder everyday functioning, thus implying an abrupt disturbance of the daily routine in the life of relatives of cancer patients.

Several studies show that caring for terminally ill patients is associated with fatigue, sleeping problems, depression, anxiety and burnout (Thomas et al., 2002). A study of 153 caregivers of patients with advanced cancer showed that over $50 \%$ of caregivers had depression scores at or near the cut-off for clinical depression. Depression was highest among female caregivers aged 45-54 years. 


\subsection{Aim}

The aim of this qualitative study is to identify the challenges encountered by family caregivers with family members under palliative care and establish the coping strategies they use.

\section{Research questions}

This study has been piloted by a vast number of questions hence the research seeks to answer the questions relating to, inter alia;

- What are the psychological and social challenges of families of patients under palliative care?

- What are the needs of families of patients under palliative care?

- What are the psychological and social coping strategies that are used by family members of people under palliative care in coping with the challenges they are facing?

\section{Research methodology}

This research employed a qualitative design in both collection and analysis of the data. Qualitative research is a type of research of social phenomenon which takes place in the natural world and uses methods that are natural and humanistic (Babbie, 2013). The qualitative design emerged as the tailormade master plan for this study as it perfectly suits exploring the experiences, thoughts and reactions of the participants.

In the present study, one-on-one interviews were conducted with the research participants in their natural everyday settings. As noted by Marshal and Rossman (2006), qualitative research is specifically effective in obtaining culturally specific information about values opinions and behaviours. Purposive sampling was used to select six family members of patients with terminal illness who were interviewed in this study. The study selected six care givers families of people receiving palliative care. The researcher approached a community health worker and selected a sample from the people visited by the community health worker. This method was employed because the researcher was looking for participants with relevant experience and knowledge for their investigation.

The researcher used a self-constructed standardised interview guide and used interviews because interviews have proved to be a better platform to investigate issues in an in-depth way, discover how individuals think and feel about a topic and why they hold certain opinions and investigate the use, effectiveness and usefulness of particular library collections and services (Cooper \& Schindler, 2003). These credentials of interviews matched the objectives of the study, hence the researcher opted for interviews with participants.

\section{Findings and discussion}

The aim of this qualitative study is to identify the challenges encountered by family caregivers with family members under palliative care and establish the coping strategies they use. The presentation of data was thus carried out in line with the research objectives which are as follows:

- To explore the psychosocial challenges of family caregivers of people receiving palliative care.

- To explore the needs of the family caregivers of people under palliative care.

- To identify the coping strategies applied by family caregivers of patients receiving palliative care. 


\section{Social challenges}

\subsection{Loneliness}

Loneliness was one of the social challenges sited by family caregivers. A 36-year-old caregiver caring for a spouse with terminal illness said 'ndinonzwa kusurukirwa nekushaya munhu wekutaura naye nekuti handichina kana shamwari nekuda kweurwere hwemurume wangu.' (I feel lonely because I do not have anyone to talk to, I lost friends because of my husband's illness.) This indicates that caring for an ill family member can create a social wall around the caregiver that begets loneliness and a deep desire to have someone to confide in. This concurs with the findings of Kellehear (2009), who observed that social isolation is one of the most widely self-reported problems associated with family caregiving. A major contributor for the reported loneliness could be the caregivers need to reduce hours of paid work, social outings and recreational outings in order to provide adequate care. Thus, in this regard, they gradually lose touch with their former circles of friends. The care giving families may also lose touch with other relatives since caring for the diseased partner may need more time and resources.

\subsection{Strained relationships with members of the extended family}

Caregivers also reported that they were experiencing conflicts with extended family members. A caregiver aged 43 said 'hama dzaamai hadzibatirane pamwe nesu, vanongoti zvionereyi sekunge tisina hukama, asi munhu arikurwara ihama yavo.' (mother's relatives do not cooperate with us, they tell us to solve our own problems, but the person who is not feeling well is their relative.) This indicated that having a family member diagnosed with a terminal illness comes along with a strain in relationships between immediate family members and members of extended families. This is in line with the research carried out by Lopez, Copp and Molassiotis (2012), indicating that diagnosis of terminal illness plunges families in the 'bad news' breaking dilemma, occupational and family roles changes negotiation, managing household and childcare, which usually result in anticipated strained family interactions.

\subsection{Restrained social mobility}

Most caregivers attested that their mobility has been restrained. One caregiver aged 51 said 'handichakwanisa kufamba, kuyenda kumichato kana pakaungana vamwe nekuti hapana anosara namai.' (I can no longer attend social gatherings such as weddings because there will be no one to look after my mother.) Kellehear (2009) echoed similar sentiments in his research findings, indicating that most caregivers forego former recreational activities to attend the demanding task of caring for a loved one battling with terminal illness.

\subsection{Role conflict}

The other challenge that is commonly pointed out by caregivers is role conflict as they try to cover the roles and responsibilities of the ill relative. A caregiver aged 51 said 'ndini ndakutomira pachinzvimbo chaamai semusikana mukuru, zvose zvinoda ivo ndini ndava kuita.' (As the eldest child, I now stand in my mother's place; all her roles are now my responsibility.) Caregivers encountered the following social challenges ranging from loneliness, restrained social mobility, strained relationships with in-laws and the extended family, as well as role conflict. This is in line with the research carried out by Kellehear (2009), which revealed that most caregivers encounter social isolation as a result of restrained social mobility and conflicts with other relatives. 


\section{Economic challenges}

It is established in the study that the caregivers in the high-density suburb of Mufakose fall in the lower stratum of the economic pyramid. Most of them have no decent earnings and are not employed. The role of being a caregiver also hinders their merger business which they engage in to earn a living.

\subsection{Increased standard of living cost and food shortage}

The interviews conducted revealed that caregivers face the challenging of trying to source income in order to meet the heightened cost of living as a result of the illness of the relative. One caregiver aged 68 said 'urwere uyu hunoda mari yakawanda nekuti tavakufanira kutenga zvakawanda kusanganisira mishonga nesipo kuti murwere agare akashambidzika, marii irikunetsa kuwana nekuti kuchengeta murwere kunodhura kunoda mari yakawanda kudarika yataimbo rarama nayo ichikwana.' (This illness requires more money because we are supposed to buy medication and detergents to ensure that the patient stays in hygienic conditions, it is difficult to get money because this illness requires more money than the amount we used to live on.) The other challenge faced by caregivers is that of food shortage. A caregiver aged 81 said 'dzimwe nguva ndinoshaya mari yekutenga chikafu chekudya nemurwere.' (Sometimes I fail to get money to buy food to eat with the patient.)A study conducted by Libble (2005) illustrated similar results and revealed that care giving can also increase standard living costs through greater energy expenditure in the home, increased travel expenses and the need to rely on ready-made or take-away meals. Aoun and Kristjanson (2005) also noted that additional costs associated with care may include purchase of equipment, bedding, home alterations, medical bills, rental equipment, respite, hygiene supplies and pharmaceuticals.

\subsection{Medical, rentals and other bills}

Medical bills and medication were presented as a major challenge by most caregivers. One caregiver aged 68 said 'dambudziko rangu guru kushaya mari yekuchipatara nemishonga inodiwa kunyaradza marwadzo emurwere.' (My biggest challenge is failure to get money to take the patient to hospital and buying medication needed to relieve the patient's pain.) Caregivers struggle to pay rentals and other bills in their day to day life. A caregiver aged 36 said 'ndinoshaya mari yerent, neye magesti uye dzimwe nguva mari yekubhadharira vana chikoro inomboshaika.' (Sometimes I don't have money to pay for rent and electrical bills and sometimes I struggle to pay school fees for my children.)Economic strain also emerged as a challenge encountered by many caregivers. The results indicated that family caregivers have financial struggles, which were evidenced by failure to pay rentals, food, medical bills and medication. Similar observations were made by Libble (2005), who cited that family caregivers generally experience heightened cost of living and vast economic strains. In agreement, Emanuel, Fairclough, Slutsman and Emanuel (2000) found that the consequences of financial hardship as a result of care have reportedly included forced selling of assets, an additional or increased loan or mortgage and the need for additional employment.

\section{Mental and physical health challenges}

\subsection{Stress, depression and anxiety}

The researcher found out that most caregivers experience psychological problems. The crumbling social world, loneliness and economic woes were portrayed as the main reasons for psychological strain. As a result, almost all caregivers reported having stress, being depressed and anxious. The psychological turmoil is caused constantly beholding the patient in aversive pain. One caregiver aged 36 said 'pfungwa dzangu dzinoremerwa ndichiona kutambura nekurwadziwa kwemurwere, ndinogara ndichizvibvunza kuti zvicharamba zvakadii kusvikira rinhi, nekuti ndinonzwa sekunge ndiri mujeri 
chairo.' (My mind is troubled seeing the patient in constant pain; I always ask myself when this will end because I feel like I am in prison.) Research findings by Thomas et al. (2009), on experience of caregivers in Australia, indicated similar findings and illustrated that family caregivers are prone to stress, depression, anxiety and general deterioration in general health. It is evident that in terms of psychological distress, the caregivers share a similar experience with caregivers in other regions

\subsection{Fatigue, disturbed sleeping patterns and decline in physical health and body mass}

Caregivers attested that they constantly feel tired because of failing to get adequate rest as a result of disturbed sleeping patterns. A caregiver aged 63 said 'ndinogara ndakaneta nekuti handiwane nguva yekurara manheru, sisi vanonwa mapiritsi anovaita kuti varare vachiyenda kuchimbuzi, saka ndinomuka ndichivaperekedza husiku hwese.' (I always feel tired, my sister is taking diuretics so she constantly visits the toilet during the night and I am the one who accompanies her to the toilet.)The other challenge which was cited was a decline in physical health and body mass. One 51-year-old caregiver said 'kubva zvakatanga kurwara amai hutano hwangu hwadzikira, ndakatoderera kunyangwe muviri wangu.' (Ever since my mother became ill, my health has deteriorated, and I have lost weight.) Similar studies reported that family members of palliative care patients experience deteriorating health and rate their health as significantly poorer compared to ratings found in a normal population. Stein et al. (2000) noted that family caregivers tend to put the needs of the ill person ahead of their own, minimising the severity of their own problems and forgoing or delaying their own healthcare. Notably, care giving is also associated with increased caregiver mortality (Siegel, Raveis, Houts \& Mor, 1991).

\section{Needs of family caregivers}

The interviews also revealed that family caregivers have a myriad of needs which come to their attention as they care for their ill relatives. The needs ranged from healthcare service needs, informational need, financial needs, psychological and practical support needs.

\subsection{Healthcare service and informational needs}

Caregivers indicated that their prime need is healthcare service. A caregiver aged 63 said 'dai zvaibvira tawana mukana wakakura wekusvika kuchipatara nguva dzese nekuwana rubatsiro rwakakwana.' (We desire to have more chances of approaching the hospital all the times and get relevant assistance.) Informational need is also another need that was cited by caregivers. A caregiver aged 80 said 'dai ndawana ruzivo pamusoro pechirwere ichi uye kuti ndingabatisire sei kuti murwere aiite zviri nani.' (I need to have more information with regard to the illness and the measures I can take to alleviate the pain.) Results showed that family caregivers have healthcare service needs. The interviews also showed that health services should provide information and psychological support to family caregivers. This concurred with Kikule's (2003) study, which noted that pain symptom and control are the key needs in home care.

\subsection{Financial needs}

Caregivers also indicated that they have financial needs.A caregiver aged 43 said 'chidiso changu chikuru kuwana mari yekubatsirikana kuchengeta murwere nekuti handina mari.' (My greatest need is to get money to use for the upkeep of the patient, because I don't have money.)Findings also indicate financial needs as the key need of caregivers. This was similar to the observation made by Harding, Leam, Pearce, Taylor and Higginson (2002), which indicated that caregivers in sub-Saharan Africa have financial needs as the prime need in caring for ill relatives. 


\subsection{Practical support need}

Obtaining practical support and aid in domestic chores is another need which was noted from the interviews. One caregiver aged 51 said 'ndinoda mumwe munhu anouya achindibatsira kuita basa repamba nekuti zvinhu zvacho zvinondiwandira.' (I need someone who can help me to do daily chores because the work is too much for me.)This is in line with Sherman's (1988) findings after interviewing caregivers and reported that $25 \%$ of the caregiving relatives reported that they had a greater need for domestic help as caregiving is taxing and time-consuming. Caregivers reported that they do not find adequate time and strength to do other domestic chores.

\subsection{Psychological needs}

Caregivers also noted that they have psychological needs including counselling. A 36-year-old caregiver said 'ndinonzwa kuda kutaura nacounselor asi nguva zhinji ndinoshaya mukana nokuti kuchipatara vanonyanya tarisa nezvemurwere kwete ini.' (I desire to talk to a counselor, but I don't get the time since at the hospital they tend to put more focus on the patient.) This concurs with Beeney, Butow and Dunn's (1995) findings which illustrated that families of terminally ill patients are subject to many conflicting emotions, including feelings of loss, sadness, guilt and distress, thus indicating that caregivers are prone to physical and psychological morbidity which needs to be catered for.

\section{Coping strategies used by family caregivers}

The research findings indicated that family caregivers employ a pool of coping strategies to mitigate the challenges they face in caring for their ill relatives. These coping strategies are presented in three categories of classification which are appraisal-focused, problem-focused and emotion-focused.

\section{Appraisal-focused coping strategy}

\subsection{Coming to terms with reality}

One of the coping strategies used by caregivers is coming to terms with reality. One caregiver aged 63 said 'ndakaona kuti kugamuchira zviripo nekuchengeta murwere nemoyo wakafara zvinoita kuti mutoro wangu ureruke.' ( $\mathrm{l}$ have seen that accepting the situation and caring for the patient with a cheerful heart makes my burden easy.)Carver and Comer-Smith (2010) found similar results and stated that relatives in palliative care describe caring as a valuable experience associated with feelings of satisfaction, gratitude and pleasure, indicating that other caregivers shift their line of thinking to cope with the challenge of caring for a relative with a terminal illness.

\subsection{Planning}

The other coping strategy employed by caregivers to mitigate their challenges is planning. A caregiver aged 68 said 'kugadzirisa dambudziko rekushomeka kwenguva nekuwanda kwebasa ndinoronga nguva yangu nebasa richaitwa nguva imwe neimwe, izvi zvinorerutsa basa rangu.' (To manage the challenge of limited time and tasks I have to perform, I have resolved to planning my work and assign each task time, this makes my work easy.) Proot et al. (2003) interviewed caregivers in Australia and reported similar results, indicating that caregivers demonstrate considerable capacity by continuing previous activities, remaining hopeful, keeping control, experiencing satisfaction and receiving support. These researchers assert that maintaining a balance between the experiences of burden and capacity is a key factor in handling challenging care situations. 


\subsection{Redefining the situation}

One caregiver indicated that redefining the current situation is one way of mitigating the challenges being faced. A caregiver aged 80 said 'ndinotarisa zvakanaka zvingabude padambudziko randakatarirasana naro uye kuti ndezvipi zvandingadzidza.' (I look for the good things which can come out this challenge, and also lessons which I can learn from this experience.) Studies by Holm, Henriksson and Wengstorm (2014) have found that family caregivers in the home are usually motivated by love and duty. Thus, indicating that looking inwardly for internal consolation and motivation is a coping strategy adopted by other caregivers. Instead of be mourning the plight before them, caregivers allow the love and bond they have for their ill relative to sooth them and be a pillar of strength to undertake the duties that lie before them.

\subsection{Problem-focused coping strategies}

\subsubsection{Seeking emotional support}

One caregiver reported that she seeks emotional support as way of coping with stress. This was outlined when a caregiver aged 36 said 'kana shungu dzandiwandira ndinofonera amai vangu kana sisi vangu ndotaura navo.' (When I am emotionally burdened, I call my mother or my sister and talk to them.) Similarly, Docherty et al. (2008) found that caregivers frequently sought a personal relationship with health professionals as a means of communicating their needs, including the need to freely discuss the patient's illness and confide difficult issues or concerns.

\subsection{Emotion-focused coping strategy}

\subsubsection{Venting emotions and religiosity}

Results also indicated that caregivers engage in venting of emotions as a way of coping with challenges. A caregiver aged 36 said 'dzimwe nguva ndinochema kuburitsa shungu.' (Sometimes I cry to let out pent up emotions.) Caregivers find a cave in religion as a way of coping with challenges. One caregiver aged 68 said 'munguva dzekuremerwa ndino namata.' (In hard times I pray.) Another caregiver said 'ndinoverenga bhaibheri kunyaradza pfungwa dzangu.' (I read the Bible to sooth my mind.)In relation to coping strategies, caregivers employed appraisal-focused coping strategies to mitigate the challenges they meet. This was in the same footing as Andershed (2006), who purports that caregivers remained positive and utilised the capacity they had to care for the ill relative and perform other daily activities.

\section{Conclusion}

Below are certain conclusions that are drawn from the findings of the study.

Care giving in families is a role that is mostly assumed by women than men. This phenomenon is found globally, although variations in its implication exist. Unemployed caregivers are more vulnerable and encounter more challenges compared to other caregivers who have a stable source of income. Care giving in high-density suburbs is more strenuous and comes along with a lot of psychosocial challenges. Psychological and financial needs are important to family caregivers in economically marginalised communities. Caring for a loved one comes along with a myriad of challenges ranging from strained relationships, depression, anxiety, disturbed sleeping patterns and financial constraints. Coping strategies used by family caregivers are partly influenced by personality, age and environment. These coping challenges range from seeking emotional support, planning, venting emotions, religiosity, coming to terms with reality and trying to find consolation in the good act of caring for the loved one. 


\section{Recommendations}

This study recommends that:

- Palliative care should include needs of caregivers and take an effectual role in empowering caregivers to mitigate challenges.

- Analysis of stress and depression levels in caregivers is necessary.

- Caregivers are encouraged to form support groups for informational and emotional support.

- Caregivers are encouraged to run self-help projects.

- Further research needs to be carried out to establish a model that can help caregivers to manage their challenges.

\section{References}

Andershed, B. (2006). Relatives in end-of-life care -- part 1: a systematic review of the literature the five last years, January 1999-February 2004. Journal of Clinical Nursing, 15(9), 1158-1169.

Aoun, S. \& Kristjanson, L. (2005). Challenging the framework for evidence in palliative care research. Palliative Medicine, 19, 461-465.

Beeney, L., Butow, P., Dunn, S. (1995). Normal adjustment to of life, how do they cope with it? Gerontology and Geriatric, 28, 264-272.

Bekelman, D. B., Hutt, E., Masoudi, F. A., Kutner, J. S. \& Rumsfeld, J. S. (2008). Defining the role of palliative care in older adults with heart failure. International Journal of Cardiology, 125(2), 183-190.

Burridge, L., Winch, S. \& Clavarino, A. (2007). Reluctance to care: a systematic review and development of a conceptual framework. Cancer Nursing, 30(2), E9-19.

Carver, C. D. \& Comer-Smith, J. (2010). Personality and coping: theory research applications. New York, NY: John Wiely.

Chokunonga, E. (2006). Annual report. 2010. Harare, Zimbabwe.

Covinsky, K. E., Goldman, L., Cook, E. F., Oye, R., Desbiens, N., Reding, D., ... Phillips, R. S. (1994). The impact of serious illness on patients' families. SUPPORT Investigators. Study to understand prognoses and preferences for outcomes and risks of treatment. JAMA, 272, 1839-1844.

Dankoski, M. E. \& Pais, S.(2007). What's love got to do with it? Journal of Couple and Relationship Therapy, 6(1-2), 31-43.

Docherty, A., Owens, A., Asadi-Lari, M., Petchey, R., Wiliams, J. \& Carter, Y. H. (2008). Knowledge and information needs of informal caregivers in palliative care: a qualitative systematic review. Palliative Medicine, 22(2), 153-171.

Donelan, K., Hill, C. A., Hoffman, C., Scoles, K., Feldman, P. H., Levine, C. \& Gould, D. (2002). Challenged to care: informal caregivers in a changing health system. Health Affairs (Millwood), 21, 222-231.

Eagar, K., Owen, A., Williams, K., Westera, A., Marosszeky, N., England, R. \& Morris, D. (2007). Effective Caring: a synthesis of the international evidence on carer needs and interventions. In Centre for Health Service Development (CHSD) (Ed.), (pp. 114). Wollongong, Australia: University of Wollongong.

Emanuel, E., Fairclough, D., Slutsman, J. \& Emanuel, L. (2000). Understanding economic and other burdens of terminal illness: the experiences of patients and their caregivers. Annual of Internal Medicine, 132(6), 451-459.

Emanuel, E. J., Fairclough, D. L., Slutsman, J., Alpert, H., Baldwin, D. \& Emanuel, L. L. (1999). Assistance from family members, friends, paid care givers, and volunteers in the care of terminally ill patients. The New England Journal of Medicine, 341, 956-963.

Grahams town Hospice. Grahams town Hospice 'Quality of Life' project.

Grant, A. (2002). Clinical features of HIV disease in developing countries. Leprosy Review, 73(2), 197-205.

Green, K. \& Horne, C. (2009). Palliative care strategy for HIV. 
Harding, R., Leam, C., Pearce, A., Taylor, E. \& Higginson, I. (2002). A multi-professional short-term group intervention for informal caregivers of patients using a home palliative care service. Journal of Palliative Care, 18(4), 275-281.

Hauser, J. M. \& Kramer, B. J. (2004). Family caregivers in palliative care. Clinics in Geriatric Medicine, 20, 671688.

Hebert, R. S. \& Schulz, R. (2006). Palliative care review: caregiving at end-of-life. Journal of Palliative Medicine, 9, 1174-1187.

Holm, M., Henriksson, A. \& Wengstorm, Y. (2014). Preparing for family caregiving in specialized palliative home care: an ongoing process. Cambridge, UK: Cambridge University.

Hupcey, J. E., Penrod, J. \& Fenstermacher, K. (2009). Review article: a model of palliative care for heart failure. American Journal of Hospice and Palliative Medicine, 26(5), 399-404.

Hupcey, J. E., Penrod, J., Fogg, J. (2009). Heart failure and palliative care: implications in practice. Journal of Palliative Medicine, 12(6), 531-536.

Jemal, A. (2011). Global cancer statistics. A Journal for Clinicians, 61(2), 69-90.

Kellehear, A. (2009). Chapter 2. Understanding the social and cultural dimensions of family care giving. In P. Hudson \& S. Payne (Eds.), Family carers in palliative care a guide for health and social care professionals (pp. 21-36). New York, NY: Oxford University Press.

Kikule, E. (2003). A good death in Uganda: survey of needs for palliative care for terminally ill people in urban areas. British Medical Journal, 327(7408), 192-194.

King, R.J.B. (2006).Cancer biology. London, UK: Pearson Education limited.

Kraus, P., Andrews, S. \& Tanchel, I. (2002). HIV infection and its implications for palliative care in South Africa. Progress in Palliative Care, 10(4), 168-171.

Lederberg, M. (1998). The family of the cancer patient. In J. Holland (Eds.), Psychooncology. New York, NY: Oxford University Press.

Libble, M. (2005). Review of existing research on the extra costs of disability. Leeds: corporate document services. to competing caregiver responsibilities. American Journal of Public Health, 90, 1138-1140.

Lopez, V., Copp, G. \& Molassiotis, A. (2012). Male caregivers of patients with breast and gynecologic cancer: experiences from caring for their spouses and partners, Cancer Nursing, 35(6), 402-410.

Lumbert, R. (2006). Palliative care amyotrophic lateral scleriosis: from diaognosis to be treavement (2nd ed.). Oxford, UK: Oxford Press.

Luttik, M. L., Blaauwbroek, A., Dijker, A. \& Jaarsma, T. (2007). Living with heart failure: partner perspectives. Journal of Cardiovascular Nursing, 22(2), 131-137.

Martensson, J., Dracup, K. \& Fridlund, B. (2001), Decisive situations influencing spouses' support of patients with heart failure: a critical incident technique analysis. Heart Lung, 30(5), 341-350.

Morris, K. (2003). Cancer? In Africa? Lancet Oncology, 4(1), 5.

Musoke, R. K. (2003). African needs: holistic approach. Proceedings of the PAPOS 2000 Conference Scientific Papers. UNAIDS. AIDS Epidemic Update. Sub-Saharan Africa. Retrieved March 3, 2004, from http://www.unaids.org/wad/2003/Epiupdate2003_en/Epi03_04_en.htm\# P64_10688

Mwaba, P., Mwansa, J., Chintu, C., Pobee, J., Scarborough, M., Portsmouth, S. \& Zumla, A. (2001). Clinical presentation, natural history, and cumulative death rates of 230 adults with primary cryptococcal meningitis in Zambian AIDS patients treated under local conditions. Postgraduate Medical Journal, 77(914), 769-773.

Proot, I. M., Abu-Saad, H. H., Crebolder, H. F. J., Goldsteen, M., Luker, K. A. \& Widdershoven, G. A. M. (2003). Vulnerability of family caregivers in terminal palliative care at home; balancing between burden and capacity. Scandinavian Journal of Caring Sciences, 17(2), 113-121.

Ramsay, S. (2001). Raising the profile of palliative care for Africa. Lancet, 358(9283), 734.

Schulz, R., Beach, S. R., Lind, B., Martire, L. M., Zdaniuk, B., Hirsch, C., ... Burton, L. (2001). Involvement in care giving and adjustment to death of a spouse: findings from the Caregiver Health Effects Study. JAMA, 285(24), 3123-3129.

Scott, L. D. (2000). Care giving and care receiving among a technologically dependent heart failure population. ANS Advances in Nursing Science, 23(2), 82-97. 
Sebern, M. \& Riegel, B. (2009). Contributions of supportive relationships to heart failure self-care. Eur J Cardiovasc Nurs, 8(2), 97-104.

Selman, L. E., Higginson, I. J., Agupio, G., Dinat, N., Downing, J., Gwyther, L., ... \& Harding, R. (2011). Quality of life among patients receiving palliative care in South Africa and Uganda: a multi-centred study. Health Qual Life Outcomes, 9(1), 21

Siegel, K., Raveis, V. H., Houts, P. \& Mor, V. (1991). Caregiver burden and unmet patient needs.Cancer, 68(5), 1131-1140.

Simpson, M. Buckman, R., Stewart, M., Maguire, P., Lipkin, M., Novack, D. \& Till, J. (1991). Doctor-patient communication: the Toronto consensus statement. British Medical Journal, 303, 1385-1387.

Stein, M. D., Crystal, S., Cunningham, W. E., Anantha narayanan, A., Andersen, R. M., Turner, B. J., ... Schuster, M. A. (2000). Delays in seeking HIV care due to competing caregiver responsibilities. Am J Public Health, 90(7), 1138-1140.

Weiderpass, E. (2010). Lifestyle and cancer risk. Journal of Preventive Medicine and Public Health, 43(6), 459-471.

Weiten, W. \& Llyod, M. A. (2008). Psychology applied in morden. Wadsworth, OH: Cennage Learning.

WHO. (2004). A community health approach to palliative care for HIV/AIDS and cancer patients in Sub-Saharan Africa. Geneva, Switzerland: World Health Organization. 